\title{
Comparison of Heat Transfer rates for Water and Ethylene Glycol mixtures for Diesel engine exhaust gas heat recovery using Shell and Tube Heat Exchanger.
}

DOI:10.36909/jer.13341

\author{
Ashok S Hadli*, S. A. Alur**, D.D.Chillal***, N. R .Banapurmath****, \\ T. M. Yunus Khan***** \\ *Department of Mechanical Engineering HSIT Nidasoshi.591236 \\ **Department of Mechanical Engineering HSIT Nidasoshi.591236. \\ ***Department of Automobile, Engineering, Basaveshwar Engineering College (Autonomous), \\ Bagalkot, Karnataka, India \\ ****School of Mechanical Engineering, B.V.B. College of Engineering and Technology, KLE \\ Technological University, Hubballi, Karnataka, India \\ ***** Research Center for Advanced Materials Science (RCAMS), King Khalid University, \\ P.O. Box 9004, Abha, 61413, Asir, Kingdom of Saudi Arabia
}

Abstract - Most of the researchers have claimed that high compression engines (diesel engines) are performing slightly above of $1 / 3^{\text {rd }}$ of their potential and remaining heat energy is wasted in the form of exhaust gas. Efforts are going on to improve the design of these engines and investigations are being carried out to recover this waste energy from exhaust gases and utilize for different applications.

In the present work, initially water is used as a heat exchange medium for three different loads on diesel engine viz., 50\%, 60\% and 70\%, which extracts heat energy to evaluate the exhaust heat attainable from exhaust gases of the engine. The exhaust gas is passed through the tube side of the heat exchanger which is obtained from an exhaust manifold of a four stroke single cylinder diesel engine. Water is passed through the shell side of the shell and tube heat exchanger. Later this work is repeated for two different cooling medium i.e. water-ethylene glycol mixtures with $25 \%$ and $50 \%$. The results are compared for $60 \%$ engine load conditions. The counter flow type 
heat exchanger arrangement is considered for the analysis. The temperatures were recorded for hot gases and cold medium at inlet and outlet points of the shell side and tube side flow. Heat calculations are carried out for each combination and detailed in the result-discussion and conclusion chapter. The objective of this work is to assess the exhaust gas heat recovery capacity using the ethylene glycol-water mixture and come out with a mixture for higher heat recovery capacity. This work is undertaken with segmental baffle heat exchanger of zero degree inclination. Also the work is repeated for inclined baffle heat exchangers of 10-degree and 20degree baffle inclination to assess the effectiveness of liquid in recovering the heat from exhaust gases. It is observed that the water and Ethylene glycol mixtures have performed satisfactorily in all three baffle setups showing only $1.5 \%-2.0 \%$ less heat recovery when compared with only water.

Keywords: Waste Heat Recovery, Diesel Engine, Shell and Tube Heat Exchanger, Ethylene Glycol, Water, Baffle.

\section{INTRODUCTION.}

In present scenario, the transportation sector (passenger and goods) heavily relies on Internal Combustion Engines (ICE's) and in the meanwhile, application of these engines has grown up considerably in the field of auxiliary power production in all common sectors and in small scale as well as heavy industries as standby units for electricity generation. It is a well known fact that diesel engines are still far from their excellences, which are unable to utilize energy released by fuel completely. Most of the heat energy is wasted in the form of exhaust gas, in cooling fluid and through radiation. Normally efficiency is the major parameter considered for performance of a system or a device. The loss of heat energy is the major factor which affects the efficiency of 
ICE's (Compression Ignition or Diesel engines). The exhaust gas with high temperature is also a leading factor for global warming and pollution of environment.

With a well known fact that the depletion of fossil fuels has increased with an alarming pace in the past and present decades and the conservation of this depleting energy to some extent by recovering and utilizing wasted energy is itself is the need of the hour. With this context many researchers have worked and still many are trying with existing and newly emerged technologies to improve performance and reduce emissions of these engines and also experimented with various techniques to recover the waste heat for further utility.

A coolant is a composition, generally a fluid that is used to regulate or reduce the thermal conditions of a system. A standard coolant should absorb and accommodate a huge amount of heat and also possess high thermal conductivity, less viscous, is low-cost, chemically inert, nonpoisonous and it should not corrode the cooling system and should not undergo phase change. It should be a good electrical insulator when used for certain specific applications.

Although the phrase "coolant" is generally used in automobiles and HVAC (Heating, Ventilation and Air conditioning) operations, and in various temperatures oriented production processes, it is often termed as Heat Transfer Fluid.

Water is a natural and largest common coolant used in many applications. It is an excellent medium for heat transaction with its high latent heat capacity and abundantly available at very low cost. But sometimes used with additives to avoid corrosion of materials, freezing and phase change. Antifreeze, a solution of a suitable organic chemical (usually Glycols) in water, is used when the water-based coolant has to withstand temperatures below $0{ }^{\circ} \mathrm{C}$, or when its boiling point has to be raised and corrosion inhibitors are used. 
Nadaf et al. discussed and assessed various recovery of waste heat technologies installed on prevailing analysis tendencies, developments and its destiny in an automotive field application. The investigation displays the opportunities with feasibility of waste heat from ICE's exhaust. Nevertheless having various possible technologies, few of them have been assessed for their advantages by utilizing these newly developed engine waste heat recovery systems with a viewpoint of environmental, economical, and technical attitudes. From the study, it's been concluded with an extensive possibility for energy achievement by employing of recovery technologies for waste heat. E.F. Doyle et al., have performed a great deal of work on Waste Heat Recovery arrangements for an ICE's exhaust gas and functional fluid, employing two distinct fluids functioning at various temperatures and pressure in two independent circuit tracks. Saiful Bari et al. assisted an experiment to regain the unfinished heat from exhaust of a C I engine with use of heat exchangers and they described that power increased up to $23.70 \%$. D. D. Chillal et al. Devised and analyzed a Modified Shell and Tube Heat Exchanger with two different baffle orientations using commercially available codes for CFD. The contribution of inclined baffles on the heat transfer rate and pressure drops is studied. Considering TEMA standards an E-type STHE was analyzed. Performed an investigation on both hot shell cold tube and cold shell hot tube heat exchangers considering water as fluid for both shell and tube side flow for the CFD study purpose. The influences of the geometrical aspects of the baffle arrangement and tube bundles on the shell side pressure drops, heat duty of the exchanger and heat transfer coefficients were analyzed. It was concluded that twenty-degree inclined baffle heat exchanger has a improved heat transfer coefficient, lesser pressure drops and a better heat duty capacity when compared with zero-degree segmental baffles for higher shell side fluid flow rates. Zhang et.al. has fabricated a standard model which can be conveniently and fortunately 
employed in an automobile for air-conditioning unit driven by engine waste heat. . E.H. Wang et al., analyzed employing distinct fluids for their functional behavior with a thermodynamic miniature created in Mat lab with REFPROP for the purpose of using in specific regions. The outcomes were related in the zones with fixing the commissioned potential at $10 \mathrm{~kW}$. They suggest that R123, R113, R141b and R11 performed somewhat better. S.Bari et al., performed an experiment to utilize the accessible heat energy in the exhaust gas of a C I engine to facilitate supplementary energy connecting a separate Rankine Cycle (RC) unit. Measured the accessible heat energy from a $40 \mathrm{~kW} \mathrm{C} \mathrm{I} \mathrm{engine} \mathrm{coupled} \mathrm{power} \mathrm{generator} \mathrm{set.} \mathrm{Using} \mathrm{water} \mathrm{as} \mathrm{the} \mathrm{working}$ medium the behavior of a feasible STHE was investigateded. The geometry of the HE was then changed to enhance the performance according to the data obtained through experiment and computer simulation. On the account of actual turbine efficiency the enhanced HE was then used to measure additional power. With this objective, two distinct heat exchangers i.e., one for vapour generation and another to create super-heated vapour. To correlate the results of organic fluids HFC-134a, Ammonia and water was also used as working medium in this experiment. It was concluded that the redesigned heat exchanger using HFC-134a, ammonia and Water as the working mediums can generate $8 \%, 9 \%$ and $10 \%$ additional power by respectively. J.E. Igwe and C.S. Agu., utilized a counter flow arranged one-shell and two-tube pass heat exchanger and worked on the correlative investigation and behavior assessment of various measures of Ethylene Glycol and Silicon carbide. The parameters concern to heat exchanger and fluids effectiveness were estimated using Mat Lab software. Examined the performance of water and Ethylene Glycol 100\% individually and mixing of Ethylene Glycol 75, 50 and 25 percents with water and 1 and 2 percent of Silicon Carbide with water as working fluids. It was concluded that the water - 
Sic 2 percent proved itself a better base fluid as it has the highest heat transfer rate of 225.32 $\mathrm{W} / \mathrm{m}^{2}{ }^{\circ} \mathrm{C}$ and highest efficiency of $57.1 \%$, resulting to higher efficiency of the system.

\section{EXPERIMENTAL SETUP.}

As mentioned earlier the main objective of this experimental work is to reclaim as much residual heat as possible from exhaust of a CI engine with the help of a Shell and Tube Heat Exchanger (STHE) using three different working fluids viz., water and water based Ethylene Glycol (EG) solutions in different proportions. The effectiveness of heat recovery with the use cooling fluids mentioned is compared. For this purpose three shell and tube heat exchangers having different baffle orientations are considered.

The CI engine used in present study is from Kirloskar oil engines ltd. made unit of $5.2 \mathrm{~kW}$ single cylinder four stroke air cooled stationary engine coupled with an Eddy current dynamometer. The specifications of the engine are given in the Table 1. The schematic diagram of the experimental set up is shown in the Figure 1.

The experiment is conducted with $60 \%$ load on engine for a constant speed of $1500 \mathrm{rpm}$ and exhaust gas temperatures were recorded. The flow rates for the exhaust gas are calculated with help of following equations. The exhaust of the engine is connected to the tube side of shell and tube heat exchanger to study the recovery rate of heat from the exhaust gas using the working fluids which were made to flow through shell side of shell and tube heat exchanger.

Air flow rate:

$\rho_{\mathrm{a}} \times \mathrm{A}_{\mathrm{a}} \times \mathrm{C}_{\mathrm{d}} \sqrt{2 \mathrm{~g} \mathrm{H}_{\mathrm{a}}}=1.0066 \times 3.14 \times 10-4 \times 0.62 \times \sqrt{2 \times 9.81 \times 69}$

$=7.21 \times 10^{-3} \mathrm{~kg} / \mathrm{s}$

Where, $\rho$ a - density of air 
$\mathrm{A}_{\mathrm{a}}-$ Cross flow area $=\pi / 4 \times(0.02) 2=3.14 \times 10-4$

$\mathrm{Cd}$ - coefficient of discharge for venturimeter $=0.62$

$\mathrm{H}_{\mathrm{a}}-$ Air head $=\left(\rho_{\mathrm{w}} \mathrm{x} \mathrm{H}_{\mathrm{w}}\right) / \rho \mathrm{\rho}[19]$

Total flow rate of exhaust gases

$2.51 \times 10-4+7.21 \times 10-3=7.454 \times 10-3 \mathrm{~kg} / \mathrm{sec}$.

Cold working fluid was primarily collected in a steel tank with a $0.75 \mathrm{~m}^{3}$ volume capacity. By adjusting the two ball valves which were placed at shell side inlet fluid line the working fluid was allowed to flow at a constant flow rate through the shell inlet nozzle. The discharge for working fluid inlet on shell side was controlled at $7.5 \mathrm{lit} / \mathrm{min}$ i.e., $0.125 \mathrm{~kg} / \mathrm{sec}$. With an utmost care the experiment was carried out observing the temperature and the discharge amounts of input and output on shell side fluid. The readings were recorded only after the steady state condition of the temperatures was observed.

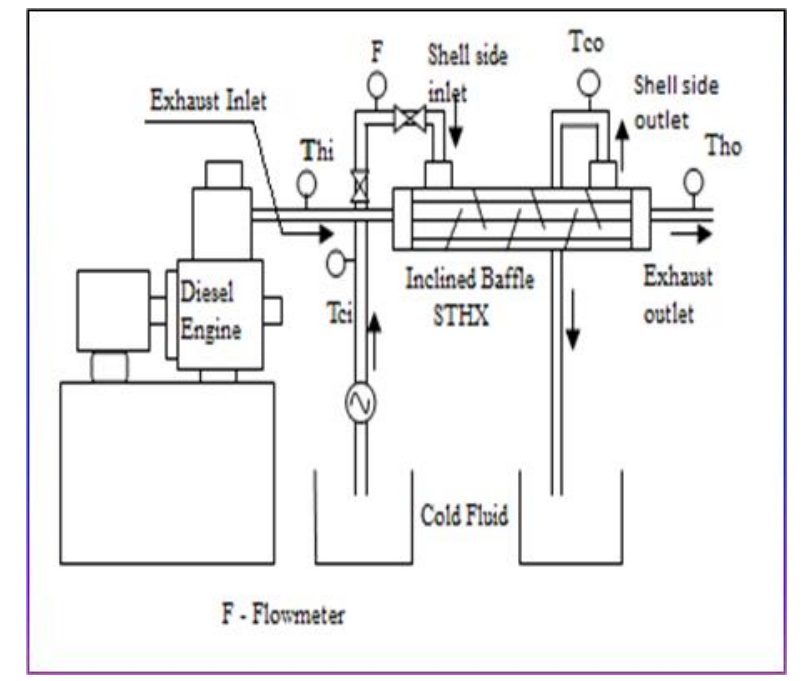

Figure.1: Schematic diagram of the experimental setup.
Table 1: Engine specifications.

\begin{tabular}{|l|l|}
\hline Manufacture & $\begin{array}{l}\text { kirloskar Oil Engines } \\
\text { Ltd. }\end{array}$ \\
\hline Engine & $\begin{array}{l}\text { Single cylinder, Four } \\
\text { stroke, Air cooled, } \\
\text { stationary C.I. Engine }\end{array}$ \\
\hline Bore & $87.5 \mathrm{~mm}$ \\
\hline Stroke & $110 \mathrm{~mm}$ \\
\hline Comp. Ratio & $17.5: 1$ \\
\hline Power Output & $5.2(7) \mathrm{kW}(\mathrm{hp})$ \\
\hline Specific Fuel & $185+5 \% \mathrm{gm} / \mathrm{hp}-\mathrm{hr}$ \\
Consumption & \\
\hline RPM & $1500 \mathrm{rpm}$ \\
\hline
\end{tabular}


For the present study a Shell and Tube heat exchanger with three different inclined baffle set is used. The specifications of heat exchanger are given in Table 2 and the following Figure 2 (a), (b) and (c) show the schematic diagrams of differently baffled heat exchangers.

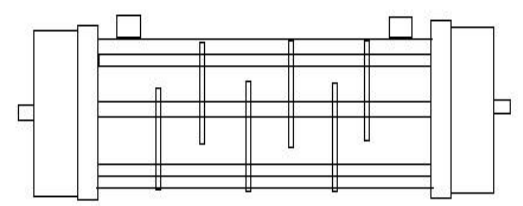

(2.a) $\quad 0^{0}$ Baffle.

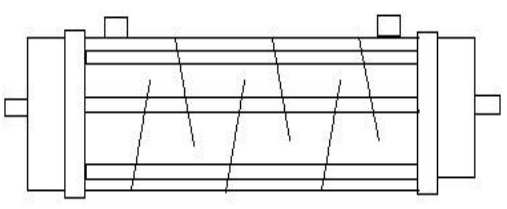

(2.b) $10^{\circ}$ Baffle.

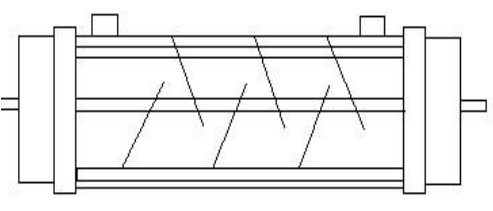

(2.c) $20^{\circ}$ Baffle

Figure.2: Schematic diagrams of Heat Exchangers with different inclinations.

And the functional fluids used to extract waste heat from exhaust gas are Water and water based Ethylene Glycol. Some of the thermo physical properties are enlisted in the following Table 3.

Table - 2: Specifications of Heat Exchanger used.

\begin{tabular}{|c|l|c|c|l|c|}
\hline Sr.No & \multicolumn{1}{|c|}{ Parameter } & Size & $\begin{array}{c}\text { Sr. } \\
\text { No }\end{array}$ & Parameter & Size \\
\hline $\mathbf{1}$ & $\begin{array}{l}\text { Length of Heat } \\
\text { Exchanger }\end{array}$ & $0.64 \mathrm{~m}$ & $\mathbf{7}$ & $\begin{array}{l}\text { No. of Tube rows cross } \\
\text { during shell flow }\end{array}$ & 3 \\
\hline $\mathbf{2}$ & Inner dia. of Shell & $0.076 \mathrm{~m}$ & $\mathbf{8}$ & Baffle thickness & $0.0015 \mathrm{~m}$ \\
\hline $\mathbf{3}$ & Outer dia. of Tube & $0.015875 \mathrm{~m}$ & $\mathbf{9}$ & Baffle spacing & $0.086 \mathrm{~m}$ \\
\hline $\mathbf{4}$ & Inner dia. of Tube & $0.01448 \mathrm{~m}$ & $\mathbf{1 0}$ & Length of flow & $0.604 \mathrm{~m}$ \\
\hline $\mathbf{5}$ & No. of Tubes & 08 & $\mathbf{1 1}$ & No. of tube passes & 1 \\
\hline $\mathbf{6}$ & No. of Baffles & 06 & $\mathbf{1 2}$ & Tube pitch & $0.02 \mathrm{~m}$ \\
\hline
\end{tabular}


An experiment with a counter flow set up is conducted using water, Ethylene Glycol solutions of $25 \%$ and Ethylene Glycol solutions of $50 \%$ as working fluids for $60 \%$ load on engine with a constant engine speed of $1500 \mathrm{rpm}$.. Water and other liquids medium are made to pass through the shell side of heat exchanger and exhaust gases passed through the tubes. The Table 4 in section III shows the temperatures of exhaust gas at inlet and outlet on tube side and water temperatures on shell side. The average specific heat for gases is taken as $1.1 \mathrm{~kJ} / \mathrm{kg} . \mathrm{K}$ and used to evaluate heat capacity of gases given in column 2 of Table 4 . The value given is a product of total flow rate of exhaust gas and specific heat.

Table - 3: Fluid Properties used in Shell and Tube Heat Exchanger.

\begin{tabular}{|c|c|c|c|c|}
\hline $\begin{array}{l}\text { properties } \Rightarrow \\
\text { Fluids } \mathbb{Z}\end{array}$ & $\begin{array}{l}\text { Density } \\
\mathrm{Kg} / \mathrm{m}^{3}\end{array}$ & $\begin{array}{l}\text { Specific Heat } \\
\text { J/kg.K }\end{array}$ & $\begin{array}{l}\text { Conductivity } \\
\text { W/ m.K }\end{array}$ & $\begin{array}{l}\text { Viscosity } \\
\text { kg/m-s }\end{array}$ \\
\hline $\begin{array}{l}\text { Water } \\
\text { at } 300^{\circ} \mathrm{K} .\end{array}$ & 990 & 4170 & 0.63 & 0.00053 \\
\hline $\begin{array}{l}\text { Ethylene Glycol } 25 \% \\
\text { at } 298^{\circ} \mathrm{K} .\end{array}$ & 1042 & 3730 & 0.48 & $1.702 * 10^{-3}$ \\
\hline $\begin{array}{l}\text { Ethylene Glycol } 50 \% \\
\text { at } 298^{\circ} \mathrm{K} .\end{array}$ & 1036 & 3161 & 0.385 & $3.90 * 10^{-3}$ \\
\hline $\begin{array}{l}\text { Exhaust gas } \\
\text { at } 619^{\circ} \mathrm{K} .\end{array}$ & 0.566 & 1055 & 0.0477 & $0.312 * 10^{-4}$ \\
\hline
\end{tabular}

\section{RESULTS AND DISCUSSION WITH TABLES AND GRAPHS.}


In this section the use of cold fluid at shell side and hot gases at tube side of heat exchanger is discussed which is limited to experimental work carried out on heat exchangers with three different baffle combinations connected to exhaust of single cylinder $5.2 \mathrm{~kW}$ diesel engine and heat is recovered by passing cold water on shell side. The discharge for working fluid inlet on shell side was controlled at $7.5 \mathrm{lit} / \mathrm{min}$ i.e., $0.125 \mathrm{~kg} / \mathrm{sec}$ for all kind of working fluids. Discussion is carried out with exit temperatures for hot gases and cold water for tube and shell side flow respectively. The discussion also includes heat recovery from hot gases with different baffle combinations and the study of effect of baffle inclination on heat recovery. For this purpose the result outputs from $0^{\circ}, 10^{\circ}$ and $20^{\circ}$ baffle inclined heat exchangers are compared in this section.

Table. 4: Observations for exhaust gas recovery experiment with $0^{0}, 10^{0}$ and $20^{0}$ segmental baffle Heat exchanger (EGHR) for water

\begin{tabular}{|c|c|c|c|c|c|}
\hline $\begin{array}{c}\text { Load on engine } \\
\text { (in \% of full } \\
\text { load) for } \\
\text { different baffle } \\
\text { inclination }\end{array}$ & $\begin{array}{c}\text { Heat } \\
\text { capacity } \\
\text { for air-gas } \\
\text { mixture in } \\
\text { KJ/K }\end{array}$ & $\begin{array}{c}\text { Exhaust } \\
\text { gas } \\
\text { temperatur } \\
\text { e at tube } \\
\text { inlet }(\mathbf{K})\end{array}$ & $\begin{array}{c}\text { Exhaust gas } \\
\text { temperature } \\
\text { at tube } \\
\text { outlet }(\mathbf{K})\end{array}$ & $\begin{array}{c}\text { Shell side } \\
\text { Water input } \\
\text { temperature } \\
\text { (K) }\end{array}$ & $\begin{array}{c}\text { Shell side } \\
\text { Water } \\
\text { output } \\
\text { temperature } \\
\text { (K) }\end{array}$ \\
\hline $60 \%$ at $0^{\circ}$ & 8.207 & 619 & 493 & 300 & 302.11 \\
\hline $60 \%$ at $10^{\circ}$ & 8.207 & 619 & 475.42 & 300 & 302.1 \\
\hline $60 \%$ at $20^{\circ}$ & 8.207 & 619 & 465.38 & 300 & 302.3 \\
\hline
\end{tabular}

The Table 5 shows temperatures at inlet and outlet for both shell and tube side fluids. And table 6. shows the heat recovered by passing cold mixtures of water with ethylene glycol at different proportions viz., $25 \%$ and $50 \%$ by volume on shell side and compared with water at only $60 \%$ load on engine. And the figure 3. shows bar graphs of heat recovered by water with comparison of heat recovery by different working fluids at $60 \%$ load on engine. 
Table 5: Comparison of experimental observations for exhaust gas recovery by water and water based Ethylene Glycol (EG) with $0^{\circ}, \mathbf{1 0}^{\circ}$ and, $20^{\circ}$ segmental baffle Heat exchanger at $60 \%$ load

\begin{tabular}{|c|c|c|c|c|}
\hline Working fluids & $\begin{array}{c}\text { Exhaust gas } \\
\text { at tube inlet } \\
(\mathrm{K})\end{array}$ & $\begin{array}{c}\text { Exhaust } \\
\text { gas } \\
\text { at tube } \\
\text { outlet } \\
\text { (K) }\end{array}$ & $\begin{array}{l}\text { Shell side } \\
\text { Fluid input } \\
\text { temperature } \\
\text { (K) }\end{array}$ & $\begin{array}{c}\text { Shell side } \\
\text { Fluid output } \\
\text { temperature } \\
(\mathbf{K})\end{array}$ \\
\hline $\begin{array}{l}\text { Exhaust gas - } \\
\text { Water }\end{array}$ & 619 & $\begin{array}{l}\text { a) } 493.08 \\
\text { b) } 475.42 \\
\text { c) } 465.38\end{array}$ & 300 & $\begin{array}{l}\text { a) } 302.11 \\
\text { b) } 302.1 \\
\text { c) } 302.3\end{array}$ \\
\hline $\begin{array}{l}\text { Exhaust gas - EG } \\
25 \%+\text { Water }\end{array}$ & 619 & $\begin{array}{l}\text { a) } 435.9 \\
\text { b) } 430.3 \\
\text { c) } 431.33\end{array}$ & 298 & $\begin{array}{l}\text { a) } 300.26 \\
\text { b) } 300.3 \\
\text { c) } 300.43\end{array}$ \\
\hline $\begin{array}{l}\text { Exhaust gas - EG } \\
50 \% \text { + Water }\end{array}$ & 619 & $\begin{array}{l}\text { a) } 435.9 \\
\text { b) } 421.29 \\
\text { c) } 422.95\end{array}$ & 298 & $\begin{array}{l}\text { a) } 300.79 \\
\text { b) } 300.88 \\
\text { c) } 300.98\end{array}$ \\
\hline
\end{tabular}

a) for $0^{\circ}$, b) for $10^{\circ}$, and c) for $20^{\circ}$ baffle inclination.

Table.6: Heat Recovered by different fluids at $60 \%$ load.

\begin{tabular}{|c|c|c|c|}
\hline $\begin{array}{l}\text { Baffle Orientation } \Rightarrow \\
\text { Fluid } \square\end{array}$ & 0 Degree & 10 Degree & 20 Degree \\
\hline Water & 990.4 & 1095 & 1198 \\
\hline Ethylene Glycol 25\% & 1090 & 1112 & 1172 \\
\hline Ethylene Glycol 50\% & 1105 & 1138 & 1181 \\
\hline
\end{tabular}




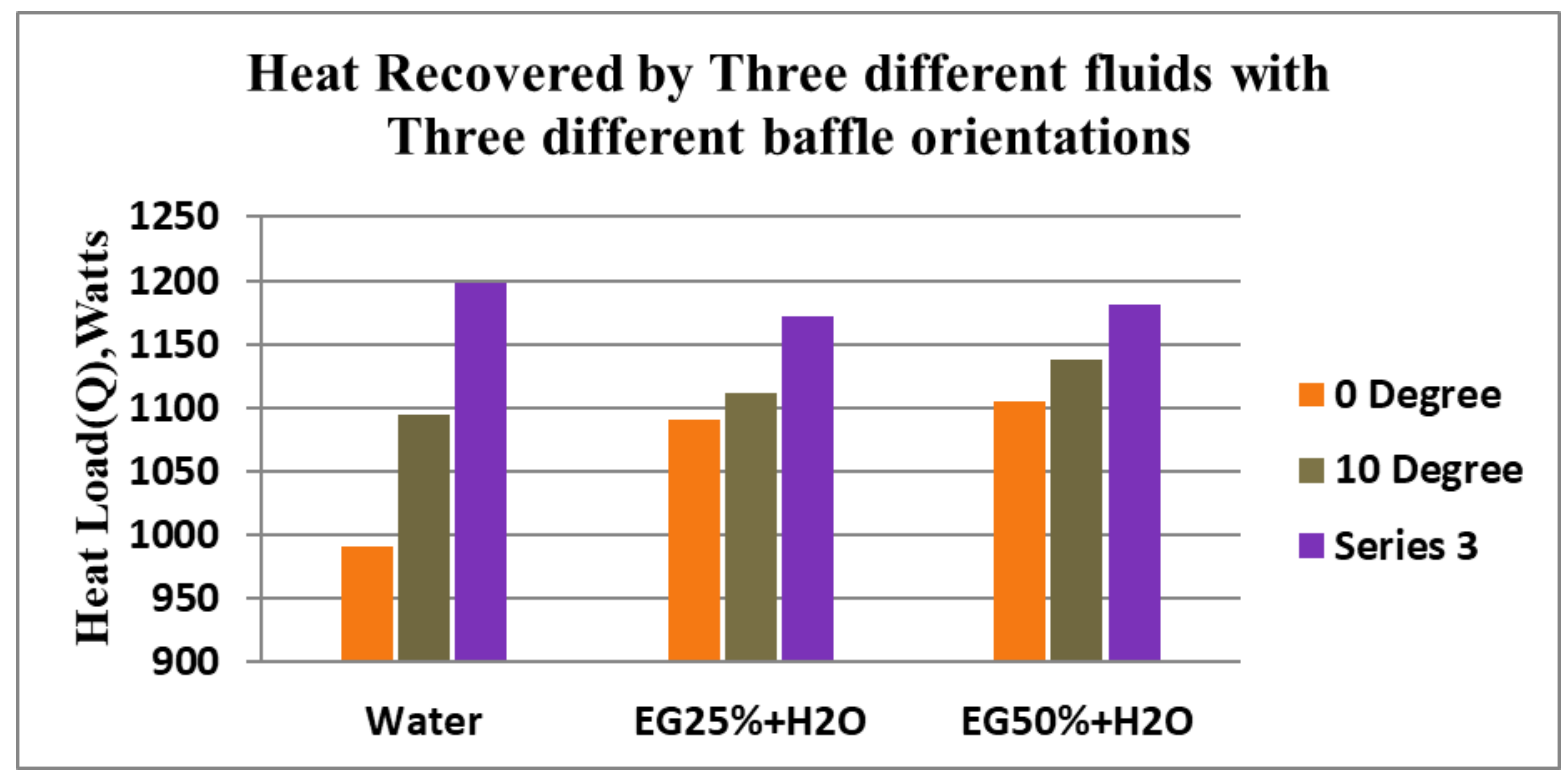

Figure.3: Bar graphs showing heat recovery by all different fluids.

When zero degree segmental baffles were used, the heat recovered by water being highest, the heat recovered by $25 \%$ ethylene glycol-water mixture was reduced by less than $2 \%$. However the heat recovered by $50 \%$ ethylene glycol-water mixture appeared to be almost same as water.With the usage of ten-degree segmental baffles, the heat recovered by $50 \%$ ethylene glycol-water mixture is the highest. Water and $25 \%$ ethylene glycol-water mixture have shown $4 \%$ and $2 \%$ less heat recovery respectively when compared with $50 \%$ ethylene glycol-water mixture.

In twenty-degree segmental baffles setup, the heat recovered by water again being highest, the heat recovered by $25 \%$ ethylene glycol-water mixture was reduced by less than $2 \%-2.5 \%$. And the heat recovered by $50 \%$ ethylene glycol-water mixture also reduced by less than $1.5 \%$..

With reference to Table 5, the following Figure. 4(a, b and c) shows the temperature difference of all fluids from inlet to outlet and compared with water at $60 \%$ load condition of engine for all three cases of heat exchanger. 


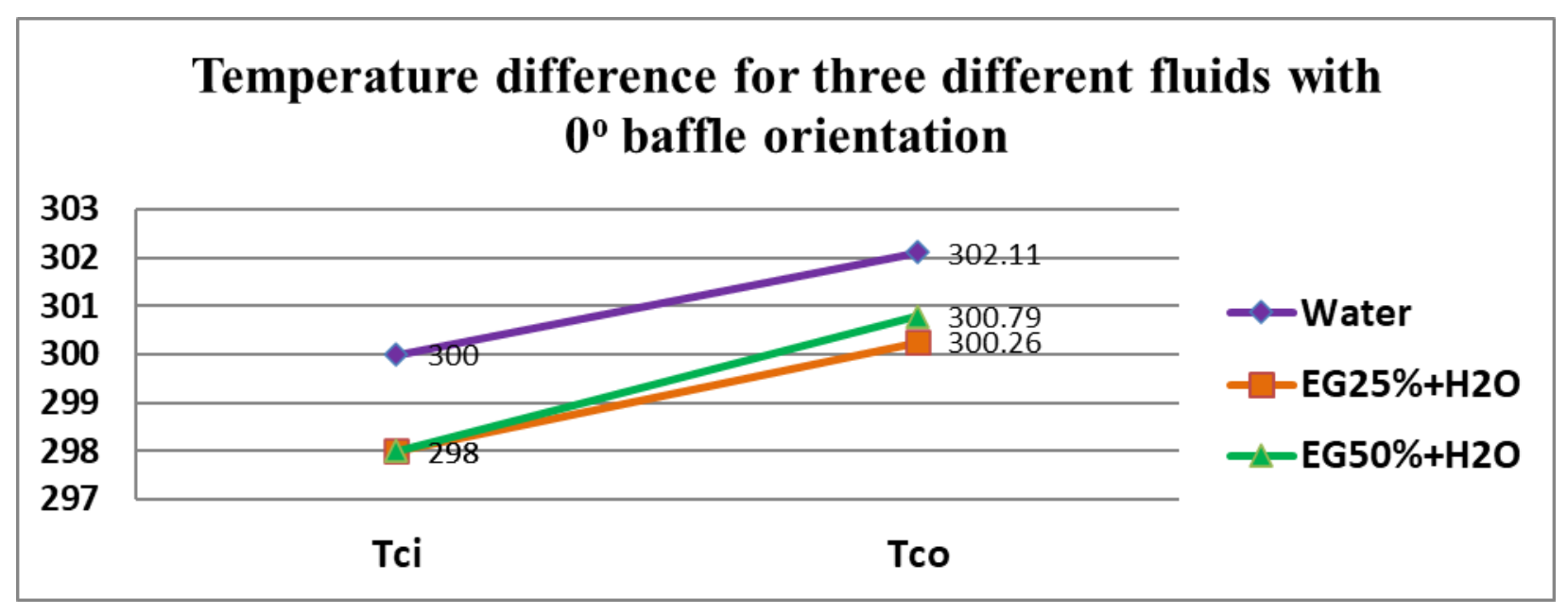

(4.a)

Temperature difference for three different fluids with $10^{\circ}$ baffle orientation

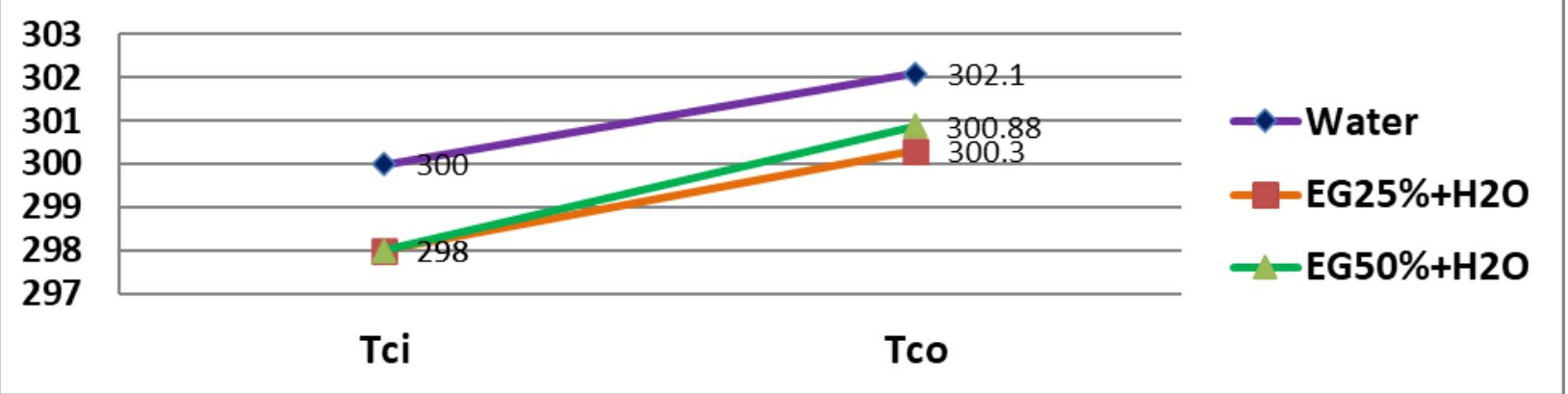

(4.b)

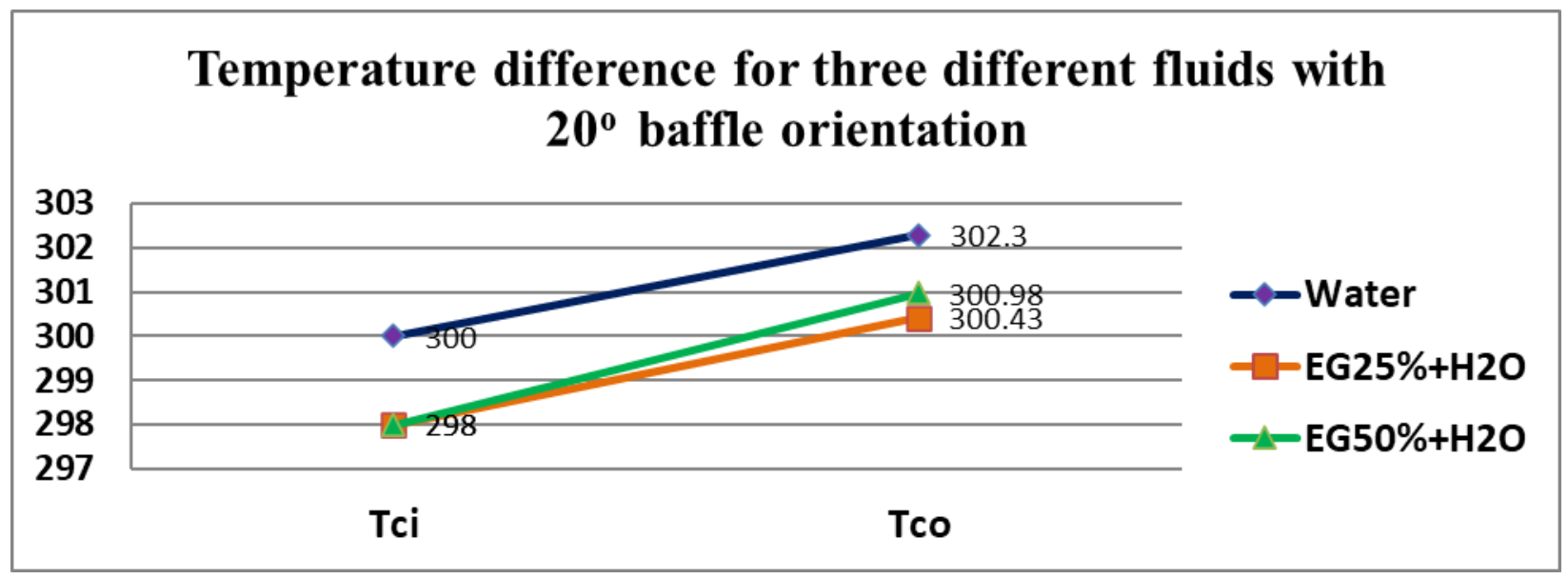


(4.c)

Figure . 4: Temperature difference of all fluids from inlet to outlet and compared with water at $60 \%$ load condition of engine for all three cases of heat exchanger.

The effectiveness of the Heat Exchanger for water and for other fluids as well at $60 \%$ load and with different baffle inclinations is tabulated in Table. 7. And the following Figures.5 shows the corresponding graphical representation of heat exchanger effectiveness for water and compares with other working fluids.

Table.7: Effectiveness of Heat Exchanger for all working fluids with particular baffle inclinations.

The effectiveness was calculated for each fluid-exhaust gas combination for three different shell and tube

\begin{tabular}{|c|c|c|c|}
\hline $\begin{array}{l}\text { Baffle Orientation } \Rightarrow \\
\text { Fluid } \square\end{array}$ & 0Degree & 10 Degree & 20 Degree \\
\hline Water & 0.394 & 0.450 & 0.481 \\
\hline $\mathrm{EG25 \%}+\mathrm{H}_{2} \mathrm{O}$ & 0.57 & 0.588 & 0.585 \\
\hline EG50\% $+\mathrm{H}_{2} \mathrm{O}$ & 0.57 & 0.616 & 0.610 \\
\hline
\end{tabular}

exchangers and comparison was made. Least effectiveness for water and highest heat effectiveness in case of both $25 \%$ and $50 \%$ of ethylene glycol -water mixture with approximately $31 \%$ increase for the latter was observed when zero degree segmental baffle STHE was used. 


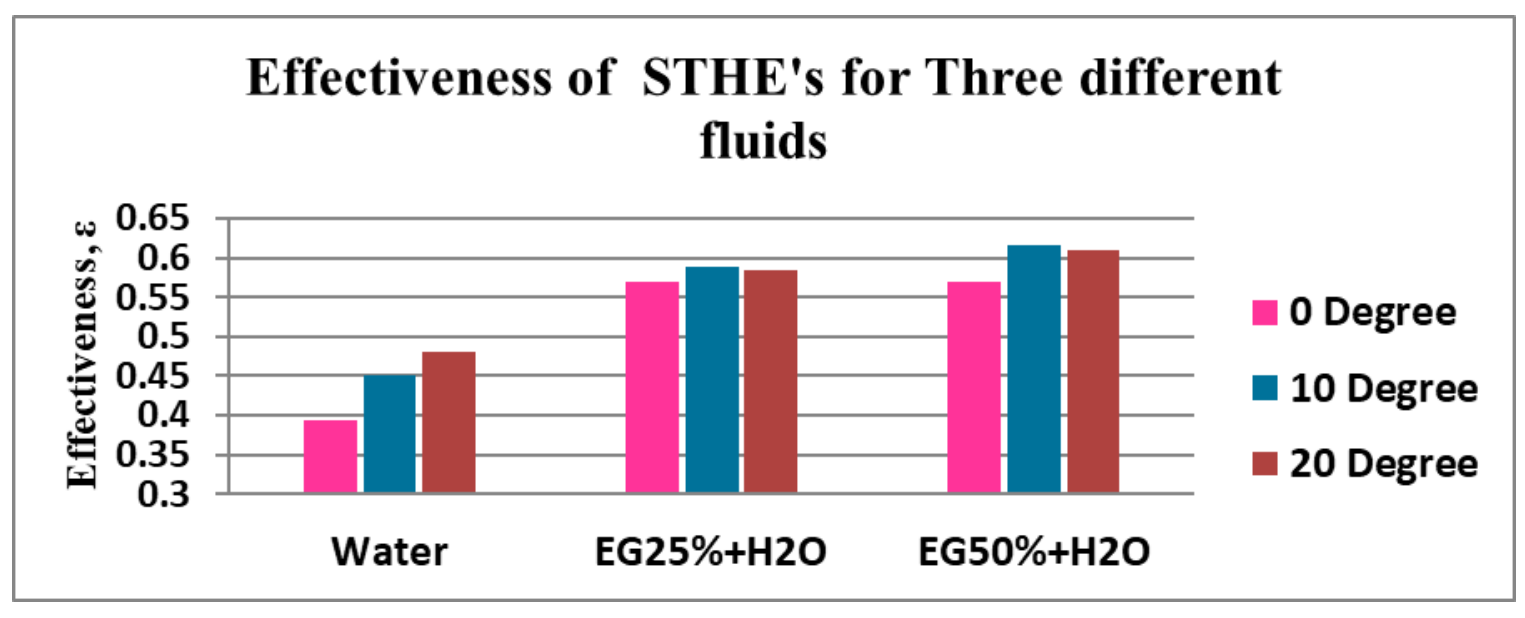

Figure.5: Comparison of effectiveness of Heat Exchangers for all working fluids.

The effectiveness for water was less and the effectiveness increased to about $24 \%$ and $27 \%$ for $25 \%$ and $50 \%$ ethylene glycol-water mixtures respectively water when ten-degree inclined baffles heat exchanger was used. A similar result has been observed with lower effectiveness for water thereby increasing to $18 \%$ for $25 \%$ ethylene glycol-water mixture and $22 \%$ for $50 \%$ ethylene glycol-water mixture when twenty-degree inclined baffles heat exchanger was used.

The following figure. 6 shows the comparison of effectiveness of heat exchanger for all different fluids with different baffle inclinations. And the Table.8 shows the observations obtained by theoretical calculations using Bell-Delaware method. And the Figure.7 shows the comparison of theoretical and experimental observations with a bar chart 


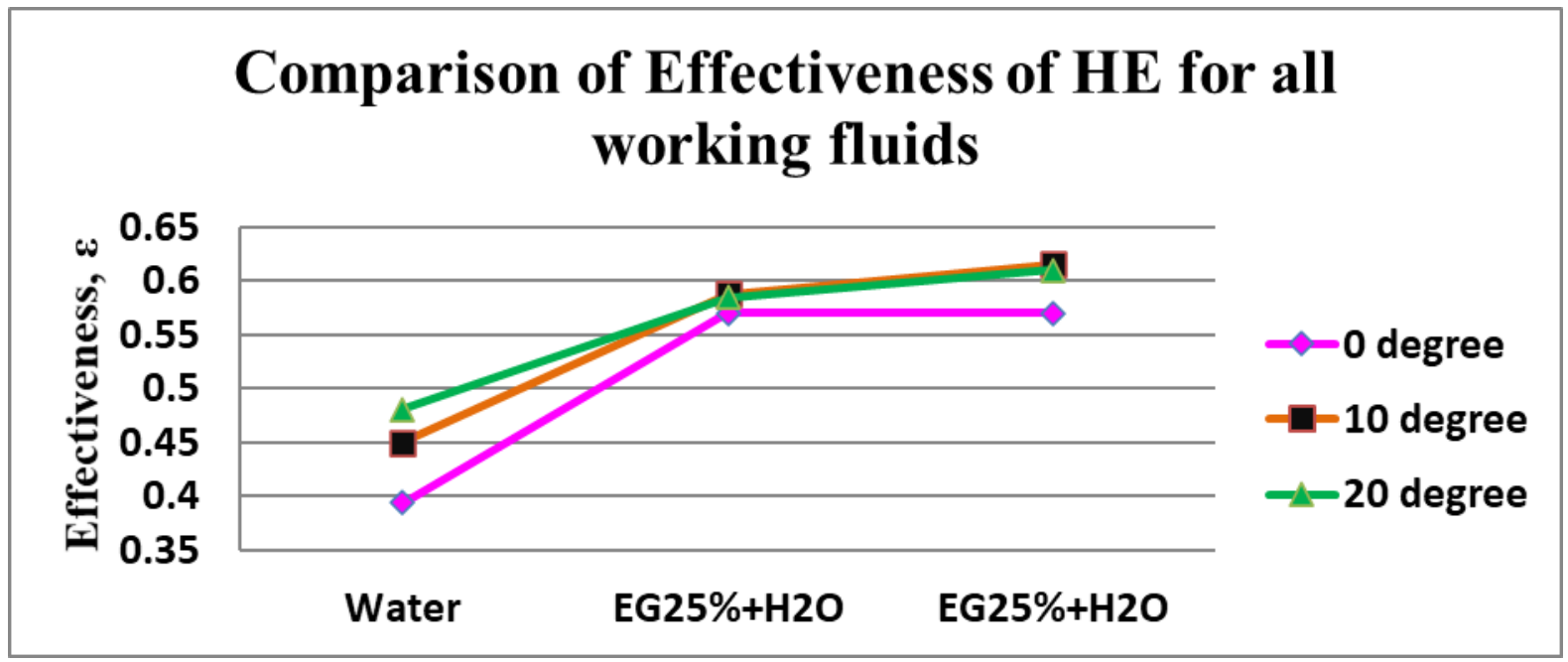

Figure.6: A Line graph of showing variation in effectiveness for the fluids with different baffle combinations.

Table.8: Theoretical observations for exhaust gas recovery by water and water based ethylene glycol with $0^{\circ}$ segmental baffle Heat exchanger at $60 \%$ load.

\begin{tabular}{|c|c|c|c|c|c|}
\hline working fluids & $\begin{array}{c}\text { Exhaust } \\
\text { gas at tube } \\
\text { inlet (K) }\end{array}$ & $\begin{array}{c}\text { Exhaust } \\
\text { gas at tube } \\
\text { outlet (K) }\end{array}$ & $\begin{array}{c}\text { Shell side } \\
\text { coolant } \\
\text { fluid input } \\
\text { temperature } \\
(\mathrm{K})\end{array}$ & $\begin{array}{c}\text { Shell side } \\
\text { coolant fluid } \\
\text { input } \\
\text { temperature } \\
\text { (K) }\end{array}$ & $\begin{array}{c}\text { Heat } \\
\text { recovered by } \\
\text { working } \\
\text { fluids (watts) }\end{array}$ \\
\hline Exhaust gas-Water & 619 & 440.36 & 300 & 302.69 & 1396.7 \\
\hline $\begin{array}{c}\text { Exhaust gas- } \\
\text { Ethylene Glycol } \\
25 \% \text { + water }\end{array}$ & 619 & 444.5 & 298 & 303.48 & 1373 \\
\hline $\begin{array}{c}\text { Exhaust gas- } \\
\text { Ethylene Glycol } \\
50 \% \text { + water }\end{array}$ & 619 & 454.4 & 298 & 302.69 & 1296 \\
\hline
\end{tabular}

The theoretical observations were calculated by using the Bel-Delaware method for a counter flow arrangement taking the inputs for $60 \%$ of full load on engine with a zero degree segmental baffle heat exchanger shown in table 8 . The theoretical and experimental observations are compared in figure 7 . The rate of heat absorption in both cases is quite close to each other having 
observed that water, $25 \%$ ethylene glycol-water mixture and $50 \%$ ethylene glycol-water mixture have shown $22 \%, 21 \%$ and $15 \%$ of difference in heat loads respectively.

\section{Comparison of Heat Load}

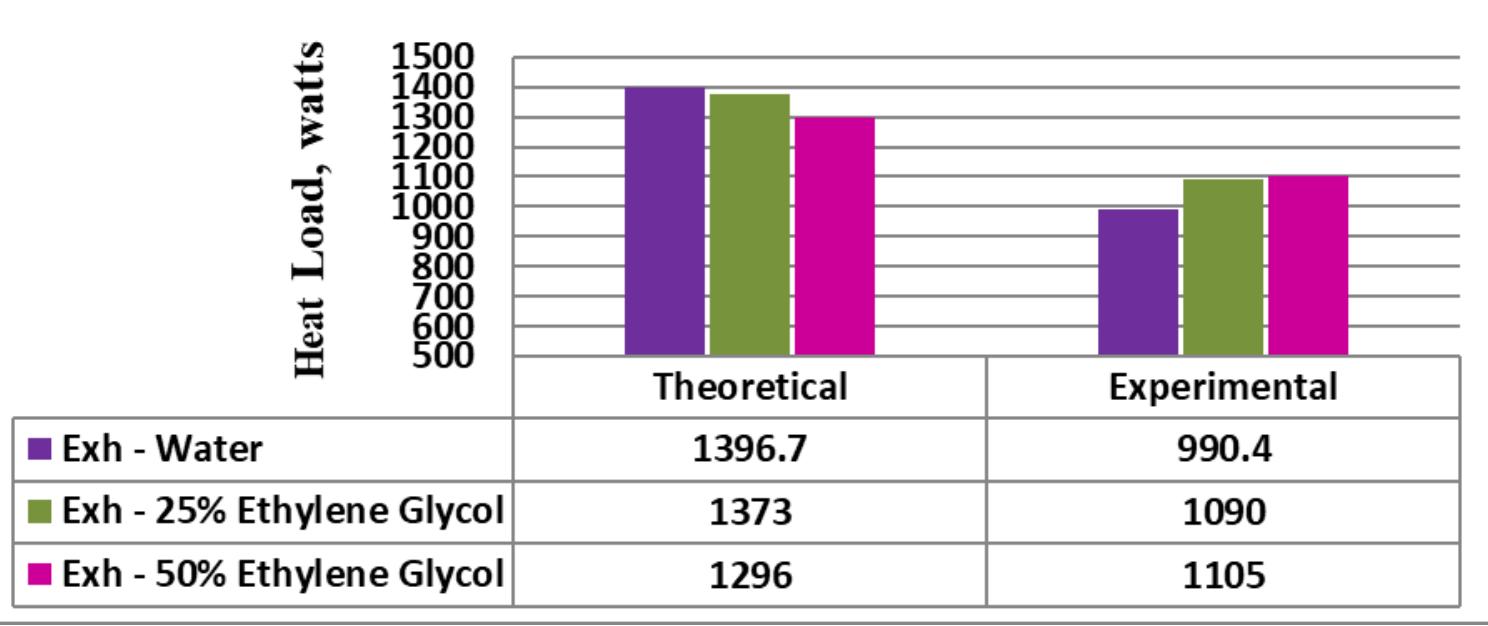

Figure.7: A bar chart shows comparison of theoretical and experimental heat loads observed with $0^{0}$ segmental baffle inclinations.

\section{CONCLUSIONS.}

In present work, mixture of $25 \%$ and $50 \%$ ethylene glycol and water, recorded less heat recovery $v i z, 2-4 \%$ and $1.5-2.5 \%$ respectively, when compared to water for zero-degree, ten-degree and twenty-degree inclined segmental baffle arrangements.

The effectiveness of heat exchanger is found to be highest for ethylene glycol-water mixture with $50 \%$ for all three heat exchanger types. 
It is concluded that the mixture of $50 \%$ of ethylene glycol and water can be an option in place of only water as heat transfer fluid to avoid the problems contained with it to some extent.

\section{ACKNOWLEDGMENT}

The authors extend their appreciation to the Deanship of Scientific Research at King Khalid University for funding this work through research groups program under grant number (R.G.P 2/105/41).

\section{REFERENCES.}

S.L Nadaf, P.B Gangavati., 2014. A Review on Waste Heat Recovery and Utilization from Diesel Engines. International Journal of Advanced Engineering Technology E-ISSN 0976-3945 Vol. V/ Issue IV/ 31-39.

E.F. Doyle, P.S. Patel. 1976, Compounding the truck diesel engine with an organic rankine cycle system, || 760343, Society of Automotive Engineers (SAE).

Saiful Bari and Sheikh N. Hossain, 2013. Waste heat recovery from a diesel engine using shell and tube heat Exchanger. Applied Thermal Engineering 61. 355- 363.

Devanand.D. Chillal, Uday C. Kapale, 2018. Study the effect of inclined baffles on heat duty for a small shell and tube heat exchanger with hot tube side fluid flow using CFD approach, International journal of Mechanical and Production engineering research and development. (IJMPERD) ISSN (P): 2249-6890; ISSN (E): 2249-8001 Vol. 8, Issue 2, 1331-1338.

Zhang L.Z. 2000. Design and testing of an automobile waste heat adsorption cooling System. Appl. Thermal Eng.; 20:103-14.

E.H.Wang et.al. 2011. Study of working fluid selection of Organic Rankine Cycle (ORC) for engine waste heat recovery. Energy, Vol.36, Issue V, Pages: 3406-3418. 
Sheikh Nisar Hossain, Saiful Bari., 2013. Waste Heat Recovery From Exhaust of a Diesel Generator Set Using Organic Fluids.10th International Conference On Mechanical Engineering, ICME

J.E. Igwe and C.S. Agu., 2016. Comparative Analysis of Different Fluids in One Shell Pass and Two Tube Heat Exchanger, American Journal of Engineering Research (AJER).,e-ISSN:23200847,p-ISSN:2320-0936,Volume-5, Issue-8,pp 81-87.

V.Pandiyarajan. M.Chinna Pandian. E. Malan. R. Velraj. R.V. Seeniraj, 2011 Experimental Investigation on Heat Recovery from Diesel Engine Exhaust Using Finned Shell and Tube Heat Exchanger and Thermal Storage System, Applied Energy 88. 77-87

Devanand.D. Chillal, Uday C. Kapale, 2018. Study the Effect of Inclined Baffles on Shell Side Liquid Flow Pressure Variation for a Small Shell and Tube Heat Exchanger with Hot Tube Side Fluid Flow using CFD Approach, International Journal of Mechanical and Production Engineering Research and Development (IJMPERD) ISSN (P): 2249-6890; ISSN (E): 22498001 Vol. 8, Issue 2, 1313-1320.

R. Saidur et.al. 2012. Technologies to recover exhaust heat from internal combustion engines. Renewable and Sustainable Energy, Reviews 16. 5649-5659.

Bijesh.P et.al. 2015. Exhaust Gas Waste Heat Recovery and Utilization System in IC Engine International Journal for Innovative Research in Science \& Technology| Volume 1 | Issue 11 | April. ISSN (online): 2349-6010.

Junjiang Bao, Li Zhao. 2013. A Review of Working Fluid and Expander Selections for Organic Rankine Cycle. Renewable and Sustainable Energy Reviews 24. 325- 342

Gequn Shu a, Xiaoning Li a, Hua Tian a, Xingyu Liang a, Haiqiao Wei , Xu Wangb., 2014. Alkanes as working fluids for high-temperature exhaust heat recovery of diesel engine using organic Rankine cycle. Applied Energy, 119, 204-217.

\section{https://www.dynalene.com/dynalene-glycol-products/}


C.P.Kothandaraman, S.Subramanyan. 2007, Heat and Mass Transfer Data Book. New Age International (p)Ltd Publishers.

Kakac S., Liu H. 2002, Heat exchangers: selection, rating, and thermal design. CRC press, Washington D C.

Dr.R.K. Bansal, Fluid mechanics and Hydraulic machines, Laxmi Publications (Pvt) Ltd. INDIA . 